\title{
Pelatihan Pembuatan Video Pembelajaran Berbasis Smartphone Android di KKG Kelas Gugus Pangeran Antasari Kota Banjarbaru
}

\author{
Muhammad Iqbal Ansari' ${ }^{1}$, Barsihanor ${ }^{2}$, M. Fahmi Arifin ${ }^{3}$ \\ Universitas Islam Kalimantan Muhammad Arsyad Al Banjari Banjarmasin \\ ${ }^{1}$ muhammadiqbalansari13@gmail.com, 2barsihanor@uniska-bjm.ac.id, \\ ${ }^{3}$ muhammadarifinalbanjari@gmail.com
}

\begin{abstract}
The spread of covid-19 in Indonesia has a huge impact in the world of education. Responding to the outbreak of the Covid-19, the government has implemented a Distance Education for education sector. The impact of the problem is experienced by many classroom teachers in Banjarbaru City, among them 1). There are still many teachers who have minimal knowledge related to learning with distance education systems, 2), There are still low skills of teachers in the creation of IT-based learning media. To solve the problem there are several solutions that the advocates offer such as 1), Providing knowledge about managing learning with distance education systems. 2). Providing knowledge about the types media platforms for distance education. 3). Providing training on making learning videos based on android smartphones through kinemaster application. Based on the results of the training on making learning videos based on android smartphones through kinemaster applications in KKG teachers of Pangeran Antasari Group class of Banjarbaru City that is well carried out, it can be concluded that the training activities are able to provide new knowledge and skills for KKG teachers in Group class of Pangeran Antasari banjarbaru city in the creation of smartphone-based learning videos through kinemaster application.
\end{abstract}

Keywords: Learning video, Smartphone

\section{Pendahuluan}

Pandemi Covid-19 berdampak besar pada aspek kehidupan manusia di dunia, tak terkecuali pada dunia pendidikan, kebijakan-kebijakan terkait dengan belajar di rumah diberlakukan guna menekan penyebaran pandemi tersebut. Kegiatan pembelajaran yang sejatinya dilaksanakan secara tatap muka dirubah menjadi pembelajaran dalam jaringan atau online. Hal ini berdasarkan imbauan Direktorat Jenderal Pendidikan Tinggi 
(Ditjen Dikti) tentang fleksibilitas pembelajaran online di Perguruan Tinggi selama dilaksanakan di masa darurat Covid-19. ${ }^{1}$

Subarto dalam Widodo, Antoni \& Rahayu menyebutkan dalam rangka menyelamatkan pendidikan di Indonesia, Kementerian Pendidikan membuat 6 kebijakan untuk mencegah carut marutnya proses pendidikan di masa pandemi, di antaranya proses Belajar Dari Rumah. ${ }^{2}$ Atiqoh menyatakan bahwa kebijakan ini menuntut orang tua untuk mendampingi anaknya selama belajar dari rumah. ${ }^{3}$ Yoga Purandina \& Astra Winaya menegaskan pula bahwa proses Belajar Dari Rumah memerlukan komunikasi yang lebih intens antara orang tua dan anak agar meningkatkan kepercayaan anak terhadap orang tuanya. ${ }^{4}$

Proses pembelajaran Jarak Jauh masih bayak guru yang kesulitan dalam pembelajaran online. Ini dikarenakan kurangnya pelatihan penggunaan teknologi dalam kegiatan pembelajaran, tentunya jika dibiarkan hal ini sangat menganggu dan berdampak pada proses pembelajaran di sekolah. Untuk itu, guru harus bisa keluar dari permasalahan tersebut, dan mencari strategi agar pembelajaran online dapat berjalan efektif, meski dengan keterbatasan yang ada. Jika guru kesulitan dalam menjangkau penggunaan teknologi mungkin guru bisa memakai platform yang paling sederhana yaitu whaatsapp grup dengan guru sebagai tutor tentunya harus dijalankan dengan kratifitas guru dalam memberikan materi-materi kepada para siswa. Rahmawati, dkk memaparkan bahwa penggunaan sistem tersebut dianggap mendapat

\footnotetext{
1 Muhammad Rifa'ie, Fleksibilitas Pembelajaran Daring Pada Masa Pandemi Covid-19 Flexibility Of Online Learning During Covid-19 Pandemic, Jurnal Pendidikan dan Kebudayaan, Vol. 5, Nomor 2, Desember 2020.

2 Widodo, Antoni, A. B., \& Rahayu, W, Peningkatan Karakter Siswa Melalui Gerakan Literasi Keluarga di Tengah Pandemi Covid-19. Transformasi Pendidikan Sebagai Upaya Mewujudkan Sustainable Development Goals (SDCs) di Era Society 5.0, 680-689.

${ }^{3}$ Atiqoh, L. N, Respon Orang Tua Terhadap Pembelajaran Daring Pada Masa Pandemi Covid-19, Thufuli : Jurnal Ilmiah Pendidikan Islam Anak Usia Dini, 2(1), 2020, 45.

${ }^{4}$ Yoga Purandina, I. P., \& Astra Winaya, I. M, Pendidikan Karakter di Lingkungan Keluarga Selama Pembelajaran Jarak Jauh pada Masa Pandemi COVID-19,Jurnal Ilmu Pendidikan, 3(2), 2020, 270-290.
}

Pelatihan Pembuatan Video Pembelajaran Berbasis Smartphone Android 
hambatan pada efektifitasnya dalam pembelajaran dalam jaringan karena guru tidak bisa memberikan penjelasan dengan optimal, minat dan motivasi siswa yang tidak terakomodasi, dan ditambah faktor ekonomi. ${ }^{5} \mathrm{Di}$ samping itu Putria, dkk memberikan tambahan bahwa belum semua peserta didik memiliki smartphone dan para orang tua yang harus bekerja sehingga tidak intensif dalam mendampingi anak dalam pembelajaran. 6

Hal tersebut juga yang diungkapkan oleh Ketua KKG Kelas Gugus Pangeran Antasari, Ibu Dina, bahwa kurangnya pelatihan terkait pembelajaran yang harus dilakukan oleh guru di saat pandemi ini membuat guru juga kebingungan untuk melakukan proses pembelajaran, sehingga pembelajaran terkesan berjalan tanpa terukur efektifitasnya. Hal itu diperparah masih banyaknya guru-guru sekolah dasar yang belum begitu mengetahui konsep pembelajaran melalui bantuan media teknologi, apalagi membuat sebuah video pembelajaran yang memanfaatkan teknologi pendidikan. Ansari \& Budi menjelaskan bahwa sangat penting bagi guru untuk mencarikan solusi agar peserta didik fokus dalam mencapai target yang direncanakan. ${ }^{7} \mathrm{Hal}$ itu lah yang menjadikan alasan utama dilakukanya pengabdian dalam bentuk pelatihan ini di mana para guru akan dilatih agar mempunyai kompetensi dalam membuat video pembelajaran berbasis smartphone.

Video pembelajaran merupakan alat peraga yang berisi materi edukatif yang digunakan untuk pembelajaran. Hendriyani, dk menyebutkan bahwa video merupakan salah satu sumber belajar berbasis audio visual dan memiliki unsur animasi gerak yang bisa meningkatkan atensi dan motivasi

${ }^{5}$ Rahmawati, N. R., Rosida, F. E., \& Kholidin, F. I, Analisis Pembelajaran Daring Saat Pandemi di Madrasah Ibtidaiyah, SITTAH: Journal of Primary Education, 1(2), 2020, 139-148,

${ }^{6}$ Putria, H., Maula, L. H., \& Uswatun, D. A, Analisis Proses pembelajaran Dalam Jaringan (DARING) Masa Pandemi COVID-19 pada Guru Sekolah Dasar, Jurnal Basicedu, 4(4), 2020, 861-872.

7 Muhammad Iqbal Ansari dan Iman Setya Budi, Pelaksanaan Program Ahlul Qur'an (ProAq) sebagari Sarana Percepatan Hafalan di Rumah Qur'an Al-Azhar Al-Syarif Kertak Hanyar Kalsel, Jurnal Pengabdian kepada Masyarakat LOYALITAS, Volume III Nomor 1 Mei 2020, 15.

Pelatihan Pembuatan Video Pembelajaran Berbasis Smartphone Android 
peserta didik dalam proses pembelajaran. ${ }^{8}$ Ningthoujam dalam Parlindungan menjelaskan cara pembelajaran melalui video memberikan bantuan kepada guru untuk meningkatkan minat belajar peserta didik melalui tampilan animasi sederhana yang mudah dimengerti. ${ }^{9}$ Latar video bisa dimanipulasi agar suasana layaknya di kelas ketika digunakan dalam pembelajaran dalam jaringan di mana peserta didik dapat melihat sosok guru saat memberikan penjelasan dalam video, bahkan lebih menarik karena latar bisa diatur agar lebih berwarna.

Peserta didik menerima pembelajaran melalui indera, terutama penglihatan dan pendengaran. Optimalisasi pembuatan video pembelajaran yang menarik akan merangsang indera tersebut, terutama pada penglihatan ketika dihadirkan dalam bentuk animasi yang berwarna, atau indera pendengaran dengan menghadirkan musik dalam video. Luhulima,dkk menyebutkan bahwa hal tersebut akan mengurangi beban berpikir peserta didik dalam menerima materi atau informasi yang disampaikan oleh guru. ${ }^{10}$ Di samping itu Puryono menjelaskan bahwa media video bermanfaat menambah minat atau ketertarikan siswa dalam belajar meskipun dilakukan secara mandiri dirumah. Karena siswa dapat menonton atau menyimak gambar dan suara dalam video tersebut.11 Siswa juga dapat memutar kembali video tersebut secara berulang-ulang jika dirasa belum bisa dipahami dengan baik.

Salah satu media yang dapat digunakan oleh guru dalam membuat video pembelajaran adalah melalui smartphone android, yaitu aplikasi

8 Hendriyani, Y., Jalinus, N., Vera Irma Delianti, \& Mursyida, L, Analisis Kebutuhan Pengembangan Media Pembelajaran Berbasis Video Tutorial, Jurnal Teknologi Informasi dan Pendidikan 11(2), 2018, 85-88.

${ }^{9}$ Parlindungan, D. P., Mahardika, G. P., \& Yulinar, D, Efektivitas Media Pembelajaran Berbasis Video Pembelajaran dalam Pembelajaran Jarak Jauh (PJJ) di SD Islam An-Nuriyah, Prosiding Seminar Nasional Penelitian LPPM UMJ, 2020, 8.

${ }^{10}$ Luhulima, D. A., Degeng, I. N. S., \& Ulfa, S, Pengembangan Video Pembelajaran Karakter Mengampuni Berbasis Animasi untuk Anak Sekolah Minggu. Jurnal Inovasi dan Teknologi Pembelajaran 3(2), 2017, 10.

${ }^{11}$ Puryono, D. A, Pelatihan Pembuatan Video Pembelajaran untuk Guru SD Kristen Terang Bagi Bangsa Pati Menggunakan Kinemaster, Jurnal Pengabdian Vokasi 01(04), 2020, 6.

Pelatihan Pembuatan Video Pembelajaran Berbasis Smartphone Android 
Kinemaster. Adnyana, Citrawathi, dan Dewi dalam Amelia mendefenisikan Kinemaster merupakan salah satu aplikasi editing video yang sangat lengkap dan mudah digunakan. Kinemaster dapat dioperasikan pada sistem operasi android dan IOS, juga disediakan dalam berbagai bahasa. Keunggulan lain dari aplikasi ini adalah ketersediaan fitur yang bisa merekam, memberi gambar, animasi, transisi, teks, perekam suara, bahkan memberi efek suara. Aplikasi ini juga tidak memberatkan pengimpanan dan kinerja smartphone karena hanya berukuran $66 \mathrm{Mb}$ (megabyte). Berbagai jenis hamparan, efek transisi, animasi, latar belakang, font tambahan, musik, bahkan memungkinkan pengguna untuk mengganti latar belakang (chroma key) agar tampilan video yang dihasilkan lebih menarik. ${ }^{12}$

Berdasarkan analisis situasi di atas, maka di identifikasi beberapa permasalahan utama untuk menerapkan pembelajaran di kelas. Kendala terkait pembelajaran tersebut, antara lain:

1. Kendala pertama, kondisi pandemi mengharuskan proses pembelajaran tidak bisa dilakukan melalui tatap muka langsung, dan menuntut pembelajaran dilakukan dengan jarak jauh atau PJJ. Kebijakan pemerintah tersebut menimbulkan permasalahan pada kemampuan guru dalam menciptakan proses pembelajaran berbasis IT. Hal ini dikarenakan pengetahuan guru yang masih dianggap rendah dalam penggunaan media teknologi dan informasi, sehingga pembelajaran secara online tidak berjalan dengan baik.

2. Kendala ketiga, masih rendahnya kreatifitas guru dalam pembuatan video pembelajaran berbasis smartphone android.

Berdasarkan permasalahan tersebut maka program pemberdayaan masyarakat ini menawarkan beberapa solusi untuk mengatasi permasalahan yang dihadapi antara lain adalah:

12 Amelia, V, Pengembangan Media Pembelajaran Berbasis Aplikasi Kinemaster Pada Pembelajaran Tematik Terpadu di Kelas III SD Negeri 36 Koto Panjang, Journal of Basic Education Studies 4(1), 2021, 12.

Pelatihan Pembuatan Video Pembelajaran Berbasis Smartphone Android 
1. Memberikan pengetahuan tentang tentang mengelola pembelajaran dengan sistem jarak jauh melalui kegiatan seminar.

2. Memberikan pengetahuan tentang jenis-jenis Platform media pembelajaran.

3. Memberikan pelatihan pembuatan video pembelajaran berbasis smartphone android.

\section{Metode}

Metode pelaksanaan kegiatan ini dengan kegiatan studi pendahuluan/identifikasi masalah dan dilanjutkan dengan kegiatan pelatihan. Metode pelatihan yang dilakukan dibagi dalam dua bagian utama, yaitu menyampaian materi media pembelajaran melalui seminar dan praktek pembuatan video pembelajaran. Adapun rangkaian kegiatan pelatihan tersebut antara lain:

\section{Studi Pendahuluan}

Melakukan kegiatan survey pendahuluan ke lokasi mitra. Hal itu dilakukan guna mengetahui kesediaan mitra untuk dengan tim pengusul dan sekaligus mengetahui permasalahan mitra setelah itu mencari serta menetapkan solusi bersama yang akan dilakukan. Disamping itu survei juga dilakukan untuk menentukan waktu pelaksanaan.

\section{Pelatihan}

Setelah proses persiapan, maka dilaksanakanlah kegiatan-kegiatan berikut ini:

a. Materi

Diawali dengan penjelasan tentang; 1) Pengertian Pembelajaran Jarak Jauh (PJJ), 2) Jenis-jenis Platform media pembelajaran dan 3) Tentang Kinemaster. 
b. Pelatihan pembuatan media

Setelah semua peserta memahami konsep pembelajaran jarak jauh (PJJ), maka tim instruktur masuk kepada sesi latihan pembuatan video pembelajaran berbasis smartphone android. Para peserta menyiapkan perlengkapan, kemudian tim instruktur menjelaskan pembuatan media secara bertahan, dan para guru mengikuti secara beriringan sampai selesai pembuatan video pembelajaran berbasis smartphone android.

c. Demontrasi penggunaan media

Setelah media selesai di buat tim instruktur mendemontrasikan bagaimana pembuatan video pembelajaran berbasis smartphone android menggunakan aplikasi Kinemaster yang dibuat,dan beberapa orang guru diminta untuk mendemontrasikan media pembelajaran yang telah ia buat.

d. Tanya jawab

Semua peserta pelatihan ini diberikan kesempatan untuk bertanya tentang sesuatu yang belum jelas, baik yang telah disampaikan dalam presentasi maupun hal-hal lain yang berkaitan dengan langkahlangkah pembuatanvideo pembelajaran berbasis smartphone android.

e. Simulasi penggunaan media

Setelah selesai tanya jawab dilakukan simulasi video pembelajaran berbasis smartphone android dengan peserta sebagai siswa, hal ini dilakukan untuk memberikan pengetahuan dan pemahaman lebih kepada peserta pelatihan.

\section{Hasil dan Diskusi}

\section{Persiapan Kegiatan}

Menjalin komunikasi dengan Ketua KKG Guru Kelas Gugus Pangeran Antasari Banjarbaru yang dilakukan beberap kali, di antaranya 29 Januari 2021, 14 Februari 2021, dan 28 Februari 2021, hal itu dilakukan untuk 
mengatur waktu dan teknis pelaksanaan sekaligus penanda tanganan surat pernyataan mitra.

2. Pelaksanaan Kegiatan

Pengabdian masyarakat dilakukan pada tanggal 10 Maret 2021. Adapun waktu pelaksanaan dimulai pada pukul 09.00 sampai pukul 12.00 WITA. Pelaksanaan dilakukan secara virtual melalui zoom meeting, hal tersebut dilakukan kerena kondisi pandemic yang sangat beresiko kalau dilakukan secara tatap muka, atas dasar kesepakatan dengan mitra, maka dilakukan secara daring. Adapun tahapan dari proses pelaksanaan kegiatan pengabdian antara lain:

a. Pemberian Materi

Metode yang digunakan dalam pemberian materi adalah metode ceramah dan diskusi. Pada kegiatan ini diwali dengan penyampaian materi tentang pembelajaran jarak jauh dan fitur Kinemaster. Pada akhir materi peserta dipersilahkan untuk bertanya kepada tim instruktur.

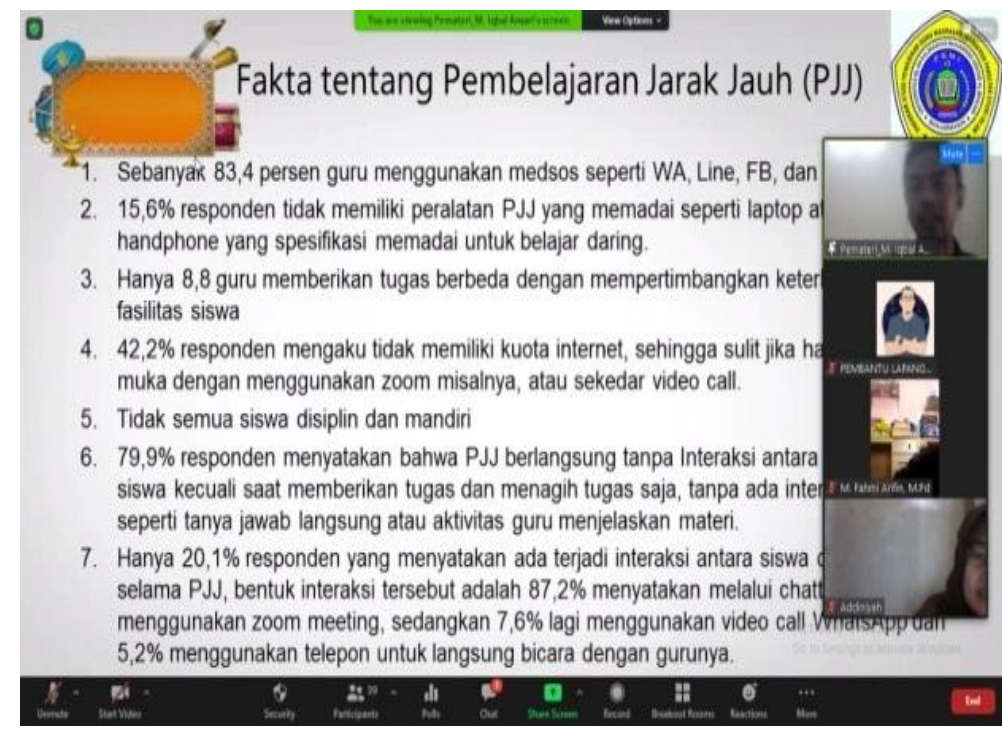

Gambar 1. Penyampaian Materi (Sumber: Dokumentasi Lapangan, 2021) 
b. Demontrasi dan simulasi penggunaan media

Setelah selesai penjelasan fitur dan penggunaan kinemaster secara umum, dilakukan demontrasi pembuatan media pembelajaran melalui kinemaster. Hal itu diawali dengan meminta para peserta untuk menginstal aplikasi kinemaster, dan setelah itu guru diminta untuk mengikuti step by step dalam pembuatan video pembelajaran.

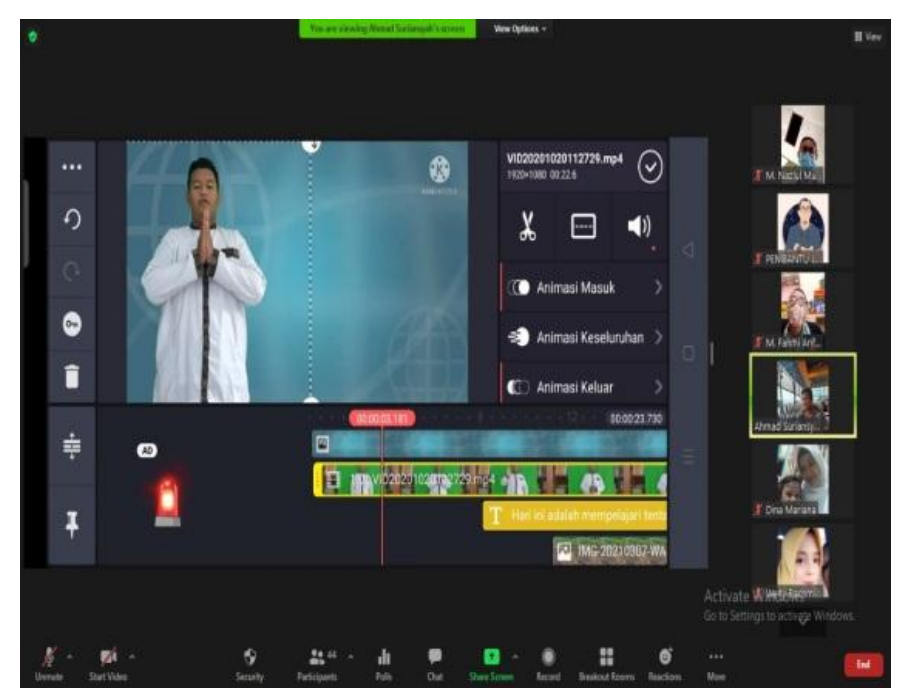

Gambar 2. Demontrasi (Sumber: Dokumentasi Lapangan, 2021)

c. Tanya jawab

Semua peserta pelatihan ini diberikan kesempatan untuk bertanya tentang sesuatu yang belum jelas, baik yang telah disampaikan dalam presentasi maupun hal-hal lain yang berkaitan dengan langkah-langkah pembuatan video pembelajaran melalui kinemaster. Langkah selanjutnya adalah Tanya jawab. Tanya jawab tersebut dilaksanakan sesudah pemaparan materi dan demontrasi pembuatan video pada kegiatan tersebut. Pertanyaan-pertanyaan yang diajukan oleh peserta ketika kegiatan tersebut berlangsung adalah sebagai berikut: 
1) Nuril Arifah (Guru)

a) Kendala yang sering dihadapi pada saat pembelajaran daring adalah jaringan, Apakah video media pembelajara dari kinemaster ini juga tergantung dengan jaringan?

b) Apakah video yang sudah dibuat tersebut dapat dikirimkan melalui grup Whatshapp?

2) Muhammad Nazlul (Guru)

Apa yang menyebabkan video nya tidak dapat dibuka setelah selesai membuat, ada banyak kasus ditemukan setelah selesai dibuat, video tidak dapat dibuka, dan bagaimana juga cara agar video tersebut menjadi lebih menarik?

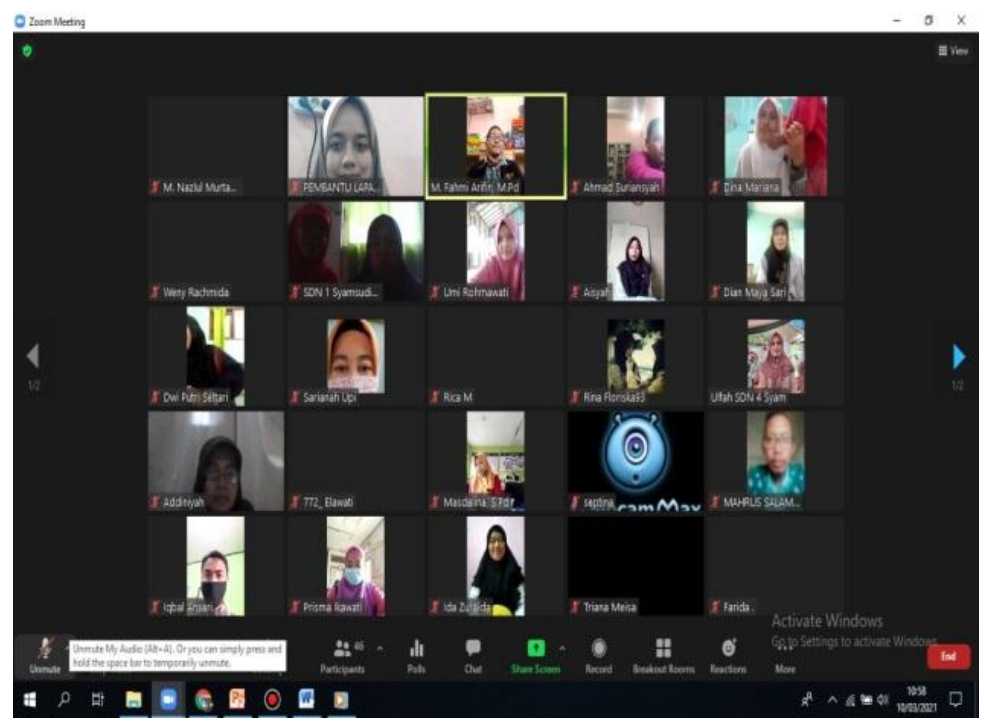

Gambar 3. Peserta Bertanya (Sumber: Dokumentasi Lapangan, 2021)

3. Evaluasi Kegiatan

Dalam rangka menilai hasil kegiatan, maka evaluasi yang dilakukan antara lain adalah dengan memberikan penilaian pada saat mengikuti pelatihan dengan membagikan angket kepada para peserta. Berikut ini adalah hasil penilaian peserta tentang kinerja kegiatan. 
Tabel 1. Hasil Penilaian Kegiatan

\begin{tabular}{|l|c|c|c|c|}
\hline \multirow{2}{*}{ Materi } & \multicolumn{3}{|c|}{ Hasil Kategorisasi } & \multirow{2}{*}{ Jumlah } \\
\cline { 2 - 4 } & Menarik & Cukup & Tidak Menarik & \\
\hline PJJ & 24 & 10 & 0 & 34 \\
\hline Fitur Kinemaster & 22 & 12 & 0 & 34 \\
\hline $\begin{array}{l}\text { Demontrasi } \\
\text { Kinemaster }\end{array}$ & 27 & 7 & 0 & 34 \\
\hline
\end{tabular}

Sumber: Dokumentasi Lapangan, 2021

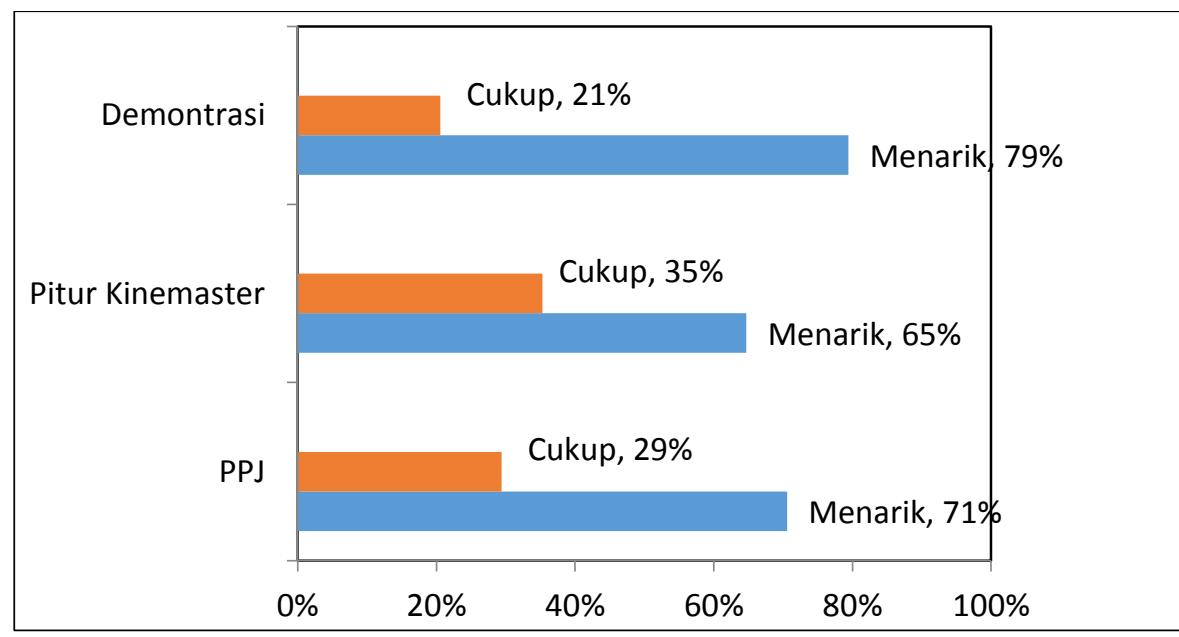

Gambar 4. Grafik Penilaian Kegiatan (Sumber: Dokumentasi Lapangan, 2021)

Berdasarkan penilaian atas materi kegiatan tersebut, terlihat bahwa keseluruhan materi kegiatan yang berisikan tentang konsep Pembelajaran Jarak Jauh, langkah-langkah penggunaan Kinemaster dan demontrasi dianggap menarik oleh seluruh peserta kegiatan.

\section{Simpulan}

Kegiatan pelatihan berjalan dengan baik dan mampu memberikan pengetahuan bagi guru-guru di KKG kelas Gugus Pangeran Antasari Kota Banjarbaru dalam pembuatan video pembelajaran berbasis smartphone melalui aplikasi kinemaster, serta memberikan keterampilan kepada guru dalam membuat video pembelajaran berbasis smartphone melalui aplikasi 
kinemaster. Penilaian peserta terhadap jalannya kegiatan pengabdian juga berada pada katagori menarik, hal itu ditunjukkan dari hasil angket yang dibagikan.

Hasil pengabdian menunjukkan antusiasme yang tinggi dari kalangan guru-guru yang tergabung dalam KKG Guru Kelas, dan memberikan dampak positif bagi guru yang meliputi aspek pengetahuan dan keterampilan, maka dari itu peneliti menyarankan agar kegiatan pelatihan-pelatihan pembuatan video pembelajaran yang menggunakan fasilitas ini dapat juga dilakukan pada tempat-tempat lain, dan kami juga menyarankan agar pengabdian yang serupa hendaknya dilakukan secara offline, demi hasil yang lebih baik lagi.

Ucapan terima kasih yang sebesar bersarnya disampaiakan Tim peneliti kepada semua pihak yang telah membantu baik material maupun dukungan moral pada pengabdian tersebut di antaranya yaitu LP2M Universitas Islam Kalimantan Muhammad Arsyad Al Banjari Banjarmasin, Ketua KKG kelas Gugus Pangeran Antasari Kota Banjarbaru sehingga pengabdian kepada masyarakat ini bisa terlaksana dengan baik. Tim juga mengucapkan terima kasih yang setinggi tingginya kepada semua guru yang telah ikut berpartisipasi dalam kegiatan pengabdian tersebut. Terimakasih pula kami ucapkan kepada pengelola Jurnal Pengabdian kepada Masyarakat Loyalitas, Institut Agama Islam Darusalam Blokagung Banyuwangi yang tela menerbitkan artikel pengabdian ini. Harapan kami ialah semoga relasi dan kerjasama yang telah terjalin dalam pengabdian ini bisa berkelanjutan dalam pengadian-pengadian dan hal-hal positif lainnya dalam rangka berupaya untuk terus meningkatkan kualitas pendidikan di Indonesia.

\section{Daftar Referensi}

Amelia, V. (2021). Pengembangan Media Pembelajaran Berbasis Aplikasi Kinemaster Pada Pembelajaran Tematik Terpadu di Kelas III SD Negeri 36 Koto Panjang. 4(1), 12.

Ansari, Muhammad Iqbal, dan Iman Setya Budi, Pelaksanaan Program Ahlul Qur'an (Pro-Aq) sebagari Sarana Percepatan Hafalan di Rumah Qur'an 
Al-Azhar Al-Syarif Kertak Hanyar Kalsel, Jurnal Pengabdian kepada Masyarakat LOYALITAS, Volume III Nomor 1 Mei 2020, 15.

Atiqoh, L. N. (2020). Respon Orang Tua Terhadap Pembelajaran Daring Pada Masa Pandemi Covid-19. Thufuli: Jurnal Ilmiah Pendidikan Islam Anak Usia Dini, 2(1), 45. https://doi.org/10.33474/thufuli.v2i1.6925

Hendriyani, Y., Jalinus, N., Vera Irma Delianti, \& Mursyida, L. (2018). Analisis Kebutuhan Pengembangan Media Pembelajaran Berbasis Video Tutorial. 11(2), 85-88.

Luhulima, D. A., Degeng, I. N. S., \& Ulfa, S. (2017). Pengembangan Video Pembelajaran Karakter Mengampuni Berbasis Animasi untuk Anak Sekolah Minggu. 3(2), 10.

Parlindungan, D. P., Mahardika, G. P., \& Yulinar, D. (2020). Efektivitas Media Pembelajaran Berbasis Video Pembelajaran dalam Pembelajaran Jarak Jauh (PJJ) di SD Islam An-Nuriyah. Prosiding Seminar Nasional Penelitian LPPM UMJ, 8.

Puryono, D. A. (2020). Pelatihan Pembuatan Video Pembelajaran untuk Guru SD Kristen Terang Bagi Bangsa Pati Menggunakan Kinemaster. 01(04), 6.

Putria, H., Maula, L. H., \& Uswatun, D. A. (2020). Analisis Proses pembelajaran Dalam Jaringan (DARING) Masa Pandemi COVID-19 pada Guru Sekolah Dasar. Jurnal Basicedu, 4(4), 861-872. https://doi.org/10.31004/basicedu.v4i4.460

Rahmawati, N. R., Rosida, F. E., \& Kholidin, F. I. (2020). Analisis Pembelajaran Daring Saat Pandemi Di Madrasah Ibtidaiyah. SITTAH: Journal of Primary Education, 1(2), 139-148. https://doi.org/10.30762/sittah.v1i2.2487

Muhammad Rifa'ie, Fleksibilitas Pembelajaran Daring Pada Masa Pandemi Covid-19 Flexibility of Online Learning During Covid-19 Pandemic, Jurnal Pendidikan dan Kebudayaan, Vol. 5, Nomor 2, Desember 2020.

Widodo, Antoni, A. B., \& Rahayu, W. (2020). Peningkatan karakter siswa melalui gerakan literasi keluarga di tengah pandemi covid-19. Transformasi Pendidikan Sebagai Upaya Mewujudkan Sustainable Development Goals (SDCs) Di Era Society 5.0, 680-689.

Yoga Purandina, I. P., \& Astra Winaya, I. M. (2020). Pendidikan Karakter di Lingkungan Keluarga Selama Pembelajaran Jarak Jauh pada Masa Pandemi COVID-19. Cetta: Jurnal Ilmu Pendidikan, 3(2), 270-290. https://doi.org/10.37329/cetta.v3i2.454 